This journal is the official publication of Bangladesh Society of Physiologists (BSP)

Web URL: www.banglajol.info/index.php/JBSP

Abstracted /indexed in Index Copernicus, Director of Open Access Journal, HINARI Index Medicus for South East Asia Region, Google Scholar, 12OR, infobse index, Open J gate, Cite factor, Scientific indexing services

pISSN-1983-1213; e-ISSN-2219-7508

\title{
Article
}

Article information:
Received: $10^{\text {th }}$ Sept 2020
Accepted: $7^{\text {th }}$ Dec 2020
DOI: https://doi.org/10.3329/jbsp.v15i2.50918

Corresponding author:

Taskina Ali, Department of Physiology, Bangabandhu Sheikh Mujib Medical University, Dhaka., Bangladesh. E-mail: taskinadr@ bsmmu.edu.bd

Cite this article:

Islam MM, Hossain MA, Bennoor KS, Ali T. Role of blood neutrophil to lymphocyte ratio and serum total IgE in the diagnosis of asthma-COPD overlap among patients with COPD.

J Bngladesh Soc Physiol 2020;15(2): 54-60

This article is open access licensed under CC BY NC SA which allows readers copy, distribute, display, and perform the work and make derivative works based on it only for noncommercial purposes.

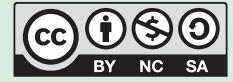

\section{Role of blood neutrophil to lymphocyte ratio and serum total IgE in diagnosis of asthma-COPD overlap among patients with COPD}

\author{
Md. Monimul Islam ${ }^{1}$, Md. Ali Hossain ${ }^{2}$, Kazi Saifuddin
}

Bennoor ${ }^{2}$, Taskina $\mathrm{Ali}^{1}$

1. Department of Physiology, Bangabandhu Sheikh Mujib Medical University, Dhaka, Bangladesh

2. Department of Respiratory Medicine, National Institute of Diseases of the Chest and Hospital, Dhaka, Bangladesh

\section{Abstract}

Background: Some clinical and spirometric features are common to both COPD and asthma-COPD overlap (ACO), causing difficulties in distinguishing these airway diseases from each other. Since, both of them are characterized by airway inflammation, any inflammatory biomarker as blood neutrophil to lymphocyte ratio and serum total $\mathrm{IgE}$ can be used for this purpose. Objectives: To assess the role of blood neutrophil to lymphocyte ratio and serum total $\mathrm{IgE}$ in the diagnosis of $\mathrm{ACO}$ among patients with COPD. Methods: This cross sectional study was conducted in the Department of Physiology, Bangabandhu Sheikh Mujib Medical University, Dhaka from March 2019 to February 2020. For this, 63 male stable patients (age 40 to 80 years) of COPD were enrolled and 51 of them were finally selected according to exclusion criteria. Then these $51 \mathrm{COPD}$ patients were divided into ACO and COPD-alone groups, based on criteria from the joint document by the Global Initiative for Asthma (GINA) and the Global Initiative for Chronic Obstructive Lung Disease (GOLD). Blood neutrophil to lymphocyte ratio (NLR) and serum total IgE of all patients were measured by standard lab procedure. For statistical analysis, Chi-Square test, Fisher exact test, Shapiro Wilk test, Mann-Whitney U test and receiver operating characteristic (ROC) curve analysis were done, as applicable. Results: Among the 51 COPD patients, 26 patients were diagnosed with $\mathrm{ACO}$ and 25 patients were with 
COPD-alone. Here, NLR was significantly lower (median 2.09 vs 3.43, respectively; $\mathrm{p}<0.001$ ) in ACO patients than that of COPD-alone. In addition, NLR showed 'very good' (area under ROC curve 0.815) diagnostic accuracy. Conclusion: The present study reveals that, blood neutrophil to lymphocyte ratio, but not serum total IgE can play substantial role in diagnosis of ACO among the patients with COPD.

Key words: Asthma-COPD overlap, COPD, blood neutrophil to lymphocyte ratio, serum total IgE, receiver operating characteristic curve, area under the curve.

\section{Introduction}

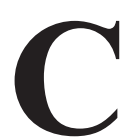
hronic obstructive pulmonary disease (COPD) and bronchial asthma are two distinct obstructive airway diseases with common pathological features, chronic airway inflammation. ${ }^{1-2}$ These two airway diseases often overlap ${ }^{3}$, where some patients with asthma present with fixed airway obstruction ${ }^{4}$ and those with COPD present with asthmatic features. ${ }^{5}$ For this group of patients, the term 'asthma-COPD overlap (ACO)' was recommended by a joint committee of Global Initiative for Asthma (GINA) and Global Initiative for Chronic Obstructive Lung Disease (GOLD). ${ }^{6}$

As per GINA-GOLD joint document, in pharmacological treatment for ACO, inhaled corticosteroid (ICS) should be included. ${ }^{6}$ Whereas, in COPD without asthmatic component, it's responsiveness is limited ${ }^{7}$ with higher risk of pneumonia. ${ }^{8}$ For this reason, patients with COPD-alone should not be treated with ICS. So, these two obstructive airway diseases should be properly identified, as well as clear differentiation between them is needed.

However, systemic inflammation might be present along with local airway inflammation in both $\mathrm{ACO}^{9}$ and COPD. ${ }^{10,-11}$ In this case, different inflammatory mediators released from inflammatory cells of local airway inflammation spill over into the systemic circulation and stimulate the hematopoietic system. As a result, different leukocytes are released from bone marrow into the bloodstream, increasing their blood count. ${ }^{12}$ Although increased count of polymorph and lymphocyte are indices of inflammation, the ratio of neutrophil to lymphocyte counts (NLR), might be a more reliable parameter for the monitoring and evaluation of systemic inflammatory response ${ }^{13}$, as it is less affected by confounding conditions, such as, exercise, mental stress, meal and in vitro handling of blood sample. ${ }^{14}$ Thus it might be more predictive for evaluating inflammation rather than the neutrophil or lymphocyte count alone. ${ }^{15-16}$

Furthermore, in asthma, among those inflammatory mediators spilled over into the systemic circulation, interleukin-4 (IL-4) and IL13 induce B-cells to secrete $\operatorname{IgE}^{17}$, which drives allergic inflammation. ${ }^{18}$ Thus, serum total $\mathrm{IgE}$ level can also be used as a marker of inflammation in this obstructive airway disease. ${ }^{19-20}$

To date, thorough clinical and spirometric evaluation are used to distinguish ACO from COPD without asthmatic components, which are subjective approaches. In addition, some common clinical features and spirometric findings ${ }^{6}$ shared by both of these obstructive airway diseases, makes it more difficult to distinguish. However, measurement of some inflammatory biomarkers, like blood NLR, as

Volume 15 No. 2 December 2020: 54-60 
well as serum total $\mathrm{IgE}$ along with those ongoing approaches might help in this aspect, which are simple and non-invasive. Moreover, blood NLR is calculated from blood neutrophil and lymphocyte counts, which can be obtained from routine cost-effective investigation, such as, complete blood count. On the basis of this background the present study was aimed to evaluate the potential role of blood NLR and serum total $\mathrm{IgE}$, to diagnose ACO among patients with COPD.

Methods

This cross sectional study was carried out at the Department of Physiology, Bangabandhu Sheikh Mujib Medical University (BSMMU) from March 2019 to February 2020. Total 63 male stable patients (age 40 to 80 years; BMI 18.6 to $24.9 \mathrm{~kg} / \mathrm{m}^{2}$ ) of COPD were purposively enrolled in this study from the Out Patient Department (OPD) of BSMMU and National Institute of Diseases of the Chest and Hospital (NIDCH). All patients were diagnosed by pulmonologists according to the GOLD criteria ${ }^{7}$, i.e. post bronchodilator forced expiratory volume in $1^{\text {st }}$ second/forced vital capacity $<0.70$. Then patients with any other pulmonary co-morbidities, inflammatory bowel disease, ischemic heart disease, any hematologic or endocrine disorder, inflammatory musculoskeletal disorder, any malignancy, hepatic dysfunction or renal insufficiency, uncontrolled systemic hypertension, diabetes mellitus, dyslipidemia, were excluded. In addition, patients with history of consuming systemic corticosteroid (within 4 weeks prior to study), as well as if they were current smoker, were also excluded from this study. Ultimately, 51 patients were selected and informed written consent was taken from all of them.

After final selection, as per syndromic approach for diagnosis of ACO proposed by GINA-GOLD joint committee ${ }^{6}$, all COPD patients were divided

Volume 15 No. 2 December 2020: 54-60 into two study groups, $\mathrm{ACO}(\mathrm{n}=26)$ and COPDalone $(n=25)$.

After collection of venous blood, neutrophil and lymphocyte count [by Fluorescence Flow Cytometry method using Sysmex XN-2000 (Sysmex America, Inc. USA) CBC analyzers], as well as, serum total IgE assay [by Chemiluminescent Immunometric Assay technique using Immulite 2000XPi immunoassay system analyzer (Siemens, USA)] of all patients were done. The NLR ratio was calculated manually.

The data were expressed as mean with standard deviation (mean $\pm \mathrm{SD}$ ), median with interquartile range and number with percentage. For statistical analysis, Chi-Square test, Fisher exact test, Shapiro Wilk test and Mann-Whitney U test were done, as applicable. Moreover, receiver operating characteristic (ROC) curve analysis with measurements of area under the ROC curve (AUC) was used to evaluate the diagnostic accuracy of these two inflammatory biomarkers for differentiating ACO from COPD. All these analyses were done using SPSS (Version 23) for Windows. In the interpretation of results, $p$ value $<0.05$ was accepted as significant.

\section{Results}

\section{Characteristics of study patients}

As shown in Table I, among a total of 51 patients, 26 patients were diagnosed with $\mathrm{ACO}$ and 25 patients were with COPD alone. However, there was no statistically significant difference of general characteristics between these two groups of patients.

\section{Blood NLR and serum total IgE}

Here, as inflammatory biomarker, NLR, but not IgE, was significantly lower $(\mathrm{p}<0.001)$ in patients with ACO, than those with COPD-alone (Table II). 
Table I: Characteristics of study patients $(\mathrm{N}=51)$

\begin{tabular}{|c|c|c|c|}
\hline Variables & $\operatorname{ACO}(n=26)$ & COPD-alone $(n=25)$ & $\mathrm{p}$ value \\
\hline$\overline{\text { Age }(\text { years) }}{ }^{\mathrm{a}}$ & $\begin{array}{c}56.9 \pm 10.6 \\
(40-75)\end{array}$ & $\begin{array}{c}61.6 \pm 9.8 \\
(45-80)\end{array}$ & $0.103^{\alpha}$ \\
\hline Weight $(\mathrm{kg})^{\mathrm{a}}$ & $\begin{array}{c}60.4 \pm 4.8 \\
(48-68)\end{array}$ & $\begin{array}{c}57.4 \pm 5.8 \\
(46-69)\end{array}$ & $0.051^{\alpha}$ \\
\hline Height $(\mathrm{cm})^{\mathrm{a}}$ & $\begin{array}{l}168.0 \pm 8.1 \\
(154-185)\end{array}$ & $\begin{array}{l}165.0 \pm 6.3 \\
(154-177)\end{array}$ & $0.276^{\alpha}$ \\
\hline $\operatorname{BMI}\left(\mathrm{kg} / \mathrm{m}^{2}\right)^{\mathrm{b}}$ & $\begin{array}{c}21.3 \\
(20.1-22.9)\end{array}$ & $\begin{array}{c}20.4 \\
(19.2-22.4)\end{array}$ & $0.317^{\beta}$ \\
\hline $\begin{array}{l}\text { Smoking status } \\
\text { - } \quad \text { Never smoker }^{\mathrm{c}} \\
\text { - } \quad \text { Ex smoker } \\
\text { - } \quad \text { Pack-years }(\text { year) }\end{array}$ & $\begin{array}{c}5(19.2 \%) \\
21(80.8 \%) \\
25.38 \pm 12.58\end{array}$ & $\begin{array}{c}2(8.0 \%) \\
23(92.0 \%) \\
29.13 \pm 8.74\end{array}$ & $\begin{array}{l}0.419^{\gamma} \\
0.254^{\alpha}\end{array}$ \\
\hline ICS Use ${ }^{c}$ & $7(26.9 \%)$ & $5(20 \%)$ & $0.743^{\delta}$ \\
\hline
\end{tabular}

Data are shown as mean $\pm \mathrm{SD}$ (a), median (interquartile range) (b) and number (percentage) (c). Statistical analysis was done by independent sample ' $t$ ' test $(\alpha)$, Mann-Whitney U test $(\beta)$, Fisher exact test $(\gamma)$, Chi-Square test $(\delta)$. $\mathrm{N}=$ total number of patients; $\mathrm{n}=$ number of patients in each group; $\mathrm{ACO}=$ asthma-COPD overlap; $\mathrm{BMI}=$ body mass index; pack-year $=($ number of cigarettes smoked per day / 20) $\mathrm{X}$ number of years smoked

Table II: Blood NLR and serum total IgE in study patients $(\mathrm{N}=51)$

\begin{tabular}{lccc}
\hline Study variables & $\mathrm{ACO}(\mathrm{n}=26)$ & COPD-alone $(\mathrm{n}=25)$ & $\mathrm{p}$ value \\
\hline Blood NLR & 2.09 & 3.43 & $0.000^{* * *}$ \\
Serum total IgE & $(1.67-2.68)$ & $(2.58-4.97)$ & 0.09 \\
& 409.6 & 220.0 & \\
\hline
\end{tabular}

Data are shown as median (interquartile range). Statistical analysis was done by Mann-Whitney U test. NLR = neutrophil to lymphocyte ratio; $\mathrm{N}=$ total number of patients; $\mathrm{n}=$ number of patients in each group; $\mathrm{ACO}=$ asthma-COPD overlap; $* * *=$ statistically significant $(\mathrm{p}<0.001)$

\section{Diagnostic performance indices of NLR}

In our study, ROC curve analysis demonstrated that, for diagnosis of ACO among COPD patients, area under the ROC curve (AUC) of NLR was found 0.815 ( $<<0.000 ; 95 \%$ confidence interval 0.697-0.934). In addition, to get the best diagnostic accuracy, the optimal cutoff value (according to highest Youden's index) ${ }^{22}$ of this variable was 2.87. Moreover, at this optimal cutoff value, the sensitivity and specificity of NLR were, 72.00 and 84.60 , respectively (Figure 1).

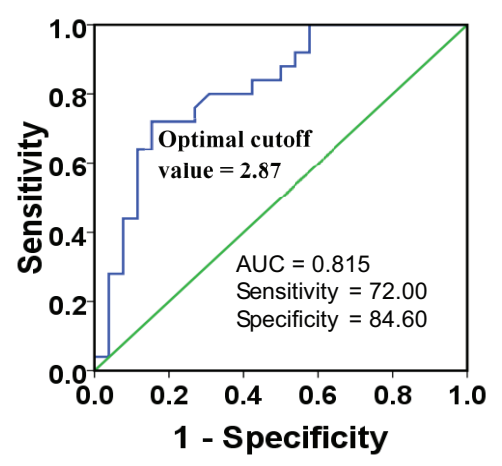

Figure 1: ROC curve of blood NLR for diagnosis of asthma-COPD overlap (ACO) among COPD patients. $\mathrm{ROC}=$ receiver operating characteristic; $\mathrm{NLR}=$ neutrophil to lymphocyte ratio; $\mathrm{AUC}=$ area under the ROC curve

Volume 15 No. 2 December 2020: 54-60 
Discussion

In this cross sectional study, NLR was significantly lower in ACO patients compared to that of COPD-alone. These observations indicate the potential role of NLR to differentiate these two closely related obstructive airway diseases. To the best of our knowledge, no previous report on similar investigation in COPD patients is available, till date.

A study on Spanish population reported that, frequency of ACO was higher ${ }^{23}$, but severity of inflammation was lower ${ }^{24}$ in biomass smokeinduced COPD than that of tobacco smokeinduced COPD. These observations might accomplish that inflammation severity would be less in ACO than that of COPD-alone. Moreover, higher increment of blood proinflammatory cytokines occurs in higher degree of inflammation ${ }^{11}$, causing high neutrophil count in blood due to profound bone marrow stimulation. ${ }^{25}$ Therefore, lower grade of inflammation severity in ACO might explain the findings of lower NLR in our ACO patients than that of COPD-alone.

In addition, serum total IgE was higher in our ACO patients than that of COPD-alone though the difference was not statistically significant. This notion was in consistence with a previous study in Thai population ${ }^{26}$, but not with another previous study inJapanese population. ${ }^{27}$ It is well known that, in asthma, IL-4 and IL-13, cytokines released from inflammatory cells ${ }^{28-30}$ can stimulate B-cells to secrete IgE. This mechanism might explain the higher serum level of this biomarker in our ACO patients than that of COPD-alone. However, a few of our study patients in both groups were on in haled corticosteroid (ICS) medication. This drug, being an anti-inflammatory agent, could cause reduction of airway inflammation, resulting in reduced release of those inflammatory mediators, causing decreased production $\mathrm{IgE} .{ }^{17}$ In addition, as ACO is more responsive to ICS than COPDalone $^{31}$, it might cause more decrement of serum total IgE in ACO, explaining no significant difference of this biomarker between two groups of our COPD patients.

Moreover, in our study, ROC curve analysis on NLR, showed AUC within range of 0.8-0.9, indicating very good diagnostic accuracy ${ }^{32}$ in diagnosing ACO among patients with COPD. In addition, at optimal cutoff value, the sensitivity of this biomarker was found $<80 \%$, indicating the more chance of false negative results. Whereas, the specificity was $>80 \%$, indicating a less chance of false positive results. However, no study was found to support these findings.

\section{Conclusion}

The present study reveals that, blood NLR, but not serum total IgE, can play a substantial role in diagnosing $\mathrm{ACO}$ among the patients with COPD.

Since, airway inflammation can be affected by ICS medication, patients with COPD with ICS should be excluded from the study. But it could not be possible due to unavailability of patients. For more precise evaluation further researches should be conducted on ICS non-user COPD patients.

Ethical Consideration: This study was approved by Institutional Review Board of BSMMU, Dhaka

\section{Conflict of interest None}

Acknowledgements

The authors wish to acknowledge to Dr. Abdul Ahad (OPD, BSMMU), for his sincere cooperation and encouragement in patient collection and to Dr. Md. Saiful Islam (Scientific Officer, Department of Physiology, BSMMU), for his proficient help in data management.

\section{References}

1. Jeffery PK. Comparison of the structural and inflammatory features of COPD and asthma. Chest 2000; 117(5 Suppl 1):251S-260S. DOI:10.1378/ chest.117.5 suppl $1.251 \mathrm{~s}$. 
2. Hogg JC, Chu F, Utokaparch S, Woods R, Elliott WM, Buzatu L, Cherniack RM, Rogers RM, Sciurba FC, Coxson HO, Paré PD. The nature of small-airway obstruction in chronic obstructive pulmonary disease. N Engl J Med 2004; 350(26):2645-2653. DOI: 10.1056/NEJMoa032158.

3. Gibson PG, Simpson JL. The overlap syndrome of asthma and COPD: what are its features and how important is it? Thorax 2009; 64(8):728-735. DOI:10.1136/thx.2008.108027.

4. Kim SR, Rhee YK. Overlap between asthma and COPD: where the two diseases converge. Allergy Asthma Immunol Res 2010; 2(4):209-214. DOI:10.4168/aair.2010.2.4.209.

5. Sin DD. Asthma-COPD overlap syndrome: what we know and what we don't. Tuberc Respir Dis 2017; 80(1):11-20. DOI:10.4046/trd.2017.80.1.11.

6. Global Initiative for Asthma, Global Initiative for Chronic Obstructive Lung Disease. Global strategy for asthma management and prevention, 2019 [Internet] [Cited April 22, 2019]. Available from: http:// www.ginasthma.org.

7. Global Initiative for Chronic Obstructive Lung Disease. Global strategy for the diagnosis, management and prevention of COPD 2019 [Internet] [Cited April 22, 2019]. Available from: http//www.goldcopd.org/ [updated 2019].

8. Singh S, Amin AV, Loke YK. Long-term use of inhaled corticosteroids and the risk of pneumonia in chronic obstructive pulmonary disease: a meta-analysis. Arch Intern Med 2009; 169(3):219-229. DOI:10.1001/ archinternmed.2008.550.

9. Girdhar A, Kumar V, Singh A, Menon B, Vijayan VK. Systemic inflammation and its response to treatment in patients with asthma. Respir Care 2011; 56(6):800805. DOI:10.4187/respcare.00601.

10. Eid AA, Ionescu AA, Nixon LS, Lewis-Jenkins V, Matthews SB, Grifûths TL, Shale DJ. Inûammatory response and body composition in chronic obstructive pulmonary disease. Am J Respir Crit Care Med 2001; 164:1414-1418. DOI:10.1164/rccm2008109.

11. Agusti AGN, Noguera A, Sauleda J, Sala E, Pons J, Busquets X. Systemic effects of chronic obstructive pulmonary disease. Eur Respir J 2003; 21(2):347360.DOI:10.1183/09031936.03.00405703.

12. Gabay C, Kushner I. Acute-phase proteins and other systemic responses to inûammation. N Engl J Med
1999; 340(6):448-454.DOI:10.1056/NEJM 199902113400607

13. Zahorec R. Ratio of neutrophil to lymphocyte countsrapid and simple parameter of systemic inflammation and stress in critically ill. Bratisl Lek Listy 2001; 102(1):5-14. PMID: 11723675.

14. Ghai CL. Staining a peripheral blood film, the differential leukocyte count (DLC). In: A textbook of practical physiology. 8th ed. New Delhi: Jaypee Brothers Medical publishers; 2013. p.69-84.

15. Azab B, Zaher M, Weiserbs KF, Torbey E, Lacossiere K, Gaddam S, Gobunsuy R, Jadonath S, Baldari D, McCord D, Lafferty J. Usefulness of neutrophil to lymphocyte ratio in predicting short- and long-term mortality after non-ST-elevation myocardial infraction. Am J Cardiol 2010; 106(4):470-476. DOI:10.1016/ j.amjcard.2010.03.062.

16. Venkatraghavan L, Tan TP, Mehta J, Arekapudi A, Govindarajulu A, Siu E. Neutrophil Lymphocyte Ratio as a predictor of systemic inflammation- A crosssectional study in a pre-admission setting. F1000Res 2015; 4:123,1-11. DOI:10.12688/f1000research. 6474.1 .

17. Takhar P, Corrigan CJ, Smurthwaite L, O'Connor BJ, Durham SR, Lee TH, Gould HJ. Class switch recombination to $\mathrm{IgE}$ in the bronchial mucosa of atopic and non-atopic patients with asthma. J allergy Clin Immunol 2007; 119(1):213-218. DOI:10.1016/ j.jaci.2006.09.045.

18. Avila PC. Does anti-IgE therapy help in asthma? Efficacy and controversies. Annu Rev Med 2007; 58:185-203. DOI:10.1146/annurev.med. 58.061705. 145252.

19. Lama M, Chatterjee M, Chaudhuri TK. Total serum immunoglobulin $\mathrm{E}$ in children with asthma. Indian $\mathrm{J}$ Clin Biochem 2013; 28(2):197-200. DOI:10.1007/ s12291-012-0247-2.

20. Cakanlar FN, Ceylan E, Kanbay A. Relationship between serum total IgE, specific IgE and serum total eosinophil counts in asthma bronchiale patients. World Allergy Organ J 2015; 8(Suppl 1):A25. DOI:10.1186/ 1939-4551-8-S1-A25.

21. World Medical Association. World Medical Association declaration of Helsinki ethical principles for medical research involving human subjects. JAMA 2013; 310(20):2191-2194 [Internet] [Cited April 18, 2019]. Available from: http://jama.jamanetwork.com. DOI:10.1001/jama.2013.281053.

Volume 15 No. 2 December 2020: 54-60 
22. Hajian-Tilaki K. Receiver operating characteristic (ROC) curve analysis for medical diagnostic test evaluation. Caspian J Intern Med 2013; 4(2):627-635. PMID:24009950.

23. Golpe R, López PS, Jiménez EC, Añón OC, Pérez-deLlano L. Distribution of clinical phenotypes in patients with chronic obstructive pulmonary disease caused by biomass and tobacco smoke. Arch Bronconeumol 2014; 50(8):318-324. DOI:10.1016/j.arbres. 2013. 12.013 .

24. Golpe R, Martín-Robles I, Sanjuán-López P, Pérezde-Llano L, González-Juanatey C, López-Campos JL, Arellano-Orden E. Differences in systemic inflammation between cigarette and biomass smokeinduced COPD. Int J Chron Obstruct Pulmon Dis 2017; 12:2639-2646. DOI:10.2147/COPD.S141068

25. Terashima T, English D, Hogg JC, van Eeden SF. The release of polymorphonuclear leukocyte from the bone marrow by interleukin 8. Blood 1998; 92(3):10621069.PMID:9680376.

26. Kawamatawong $\mathrm{T}$, Charoenniwassakul $\mathrm{S}$, Rerkpattanapipat $\mathrm{T}$. The asthma and chronic obstructive pulmonary disease overlap syndrome in tertiary care setting Thailand. Asia Pac Allergy 2017; 7(4):227-233. DOI:10.5415/apallergy.2017.7.4.227.

27. Kobayashi S, Hanagama M, Yamanda S, Ishida M, Yanai M. Inflammatory biomarkers in asthma-COPD overlap syndrome. Int J Chron Obstruct Pulmon Dis 2016; 11(1):2117-2123. DOI:10.2147/COPD. S113647.

28. Kay AB. The role of T lymphocytes in asthma. Chem Immunol Allergy 2006; 91:59-75. DOI:10.1159/ 000090230 .

29. Froidure A, Mouthuy J, Durham SR, Chanez P, Sibille Y, Pilette C. Asthma phenotypes and IgE responses. Eur Respir J 2015; 47(1):304-319. doi: 10.1183/ 13993003.01824-2014.

30. Robinson D, Humbert M, Buhl R, Cruz AA, Inoue H, Korom S, Hanania NA, Nair P. Revisiting type 2-high and type 2-low airway inflammation in asthma: current knowledge and therapeutic implications. Clin Exp Allergy 2016; 47(2):161-175. doi: 10.1111/cea.12880.

31. Kitaguchi Y, Komatsu Y, Fujimoto K, Hanaoka M, Kubo K. Sputum eosinophilia can predict responsiveness to inhaled corticosteroid treatment in patients with overlap syndrome of COPD and asthma. Int J Chron Obstruct Pulmon Dis 2012; 7:283-289. DOI:10.2147/COPD.S30651.

32. Okeh UM, Okoro CN. Evaluating measures of indicators of diagnostic test performance: fundamental meanings and formulars. J Biomet Biostat 2012; 3(1):132(1-10). DOI:10.4172/2155-6180.1000132. 